\title{
O USO DE AMINAS GRAXAS E SEUS DERIVADOS NA FLOTAÇÃO DE MINÉRIOS BRASILEIROS
}

\author{
Euler Elias Neder ${ }^{1}$ e Laurindo de Salles Leal Filho ${ }^{2}$ \\ ${ }^{1}$ Mestre em Engenharia Mineral - EPUSP \\ euler.neder@sc.akzonobel.com \\ ${ }^{2}$ Professor Titular (Livre Docente) - EPUSP \\ lauleal@usp.br
}

Trabalho apresentado no XXI ENTMME, Natal-RN, novembro, 2005

\begin{abstract}
RESUMO
Os coletores catiônicos têm sido utilizados na flotação de minerais desde o final dos anos 30 e a química desses compostos é baseada nas aminas e seus derivados. No Brasil, esses produtos estão entre os principais reagentes utilizados pela indústria mineral. A utilização dessa classe de produtos como coletores de flotação é mundialmente reconhecida em processos de concentração de sais solúveis e oximinerais. Mesmo assim, apesar de sua grande aplicação, existem poucas publicações em português que reúnem e conectam os conceitos de flotação com as propriedades das aminas. Nesse trabalho, discorreu-se sobre a química desses compostos discutindo e revisando suas rotas de produção industrial, as variáveis que afetam a qualidade, as propriedades das aminas como tensoativos e a sua correlação com os processos de flotação. Além disso, os mecanismos de coleta em sais solúveis e oximinerais foram detalhados. Ao final do trabalho foram apresentadas sugestões de usos de moléculas já existentes bem como de novos produtos que têm potencial aplicação como coletores.
\end{abstract}

Palavras chave: Coletores, flotação.

\section{THE USE OF AMINES CREASES AND DERIVATES IN FLOTATION OF BRAZILIAN MINERALS}

\begin{abstract}
Cationic collectors have being utilized in froth flotation since the end of 30's and their chemistry are based on fatty amines and their derivatives. In Brazil, those chemicals are among the most important reagents used by the mineral industry. Their application as collectors are well known and recognized worldwide in flotation processes of soluble salts, silicates and other oxidized ores. Despite of the extensive use, the availability of local publications covering their chemistry and applications are limited. This work primarily reviews the amine based products used as flotation collectors discussing their industrial production routes, variables affecting the quality, the properties of the amines as surfactants and the correlation of those properties with the flotation processes. The interaction mechanisms of amines and minerals (soluble salts, oxides and silicates) were discussed in the light of their chemistry and properties. The reminder of the thesis suggests that some new and existing amines could be exploited by the industry as an option for the collectors presently in use.
\end{abstract}

Keywords: Collectors, flotation. 


\section{O USO DE AMINAS GRAXAS E SEUS DERIVADOS NA FLOTAÇÃO DE MINÉRIOS BRASILEIROS}

\section{INTRODUÇÃO E OBJETIVOS}

Dentre os diversos produtos químicos que são utilizados no processo de flotação, as aminas e seus derivados são particularmente relevantes porque são responsáveis pela concentração de importantes minérios brasileiros. Estima-se que aproximadamente 5.500 toneladas de derivados de aminas sejam utilizados anualmente no Brasil em processos de concentração de hematita, willemita, calamina, pirocloro, calcita, magnesita, silvita e alguns tipos de apatita.

Os assuntos de química orgânica e de tensoativos, dos quais as aminas fazem parte, são pouco explorados pelas ementas dos cursos de engenharia de minas, de modo que os engenheiros tratamentistas têm limitações para entender a influência dos coletores catiônicos que são usados na usina de concentração. Para auxiliar na compreensão das propriedades e características físico-químicas das aminas e seu comportamento enquanto agentes de flotação, definiu-se alguns objetivos para esse trabalho:

i. Revisar as rotas de produção das aminas utilizadas em processos de flotação. i.i. Fazer uma revisão da literatura desses produtos como tensoativos e coletores. i.i.i. Correlacionar as propriedades das aminas com os processos de flotação de minérios revisando seus mecanismos de atuação.

\section{DEFINIÇÕES, ROTAS DE PRODUÇÃO E CONTROLE DE QUALIDADE}

Diversos autores [1-3] definem as aminas de maneira genérica como sendo uma molécula de amônia, $\mathrm{NH}_{3}$, ou derivada dela, onde um, dois, ou os três átomos de hidrogênio são substituídos pôr grupos alifáticos monovalentes. O "Condensed Chemical Dictionary" [2] é mais abrangente, definindo as aminas graxas como sendo um composto derivado da amônia, alifático, cujas matérias primas principais são óleos ou gorduras, saturadas ou não, classificando-se como primárias, secundárias ou terciárias e que possuem cadeia carbônica com um número par de átomos de carbonos variando entre 8 e 22. Essa definição seria perfeita, a não ser pela limitação de não incluir os derivados de aminas geradas a partir de álcoois sintéticos, cuja cadeia não é necessariamente composta por um número par de carbonos.

As aminas graxas tem em sua molécula uma parte de origem oleosa, cuja fonte pode ser tanto animal, vegetal ou mesmo mineral. Essa porção oleosa é hidrofóbica e está ligada ao nitrogênio, que tem um par de elétrons não compartilhados em sua camada de valência, apresentando características iônicas. Da mesma forma que a amônia, os compostos nitrogenados trivalentes, os quais podem ser definidos como amônias substituídas, são consideradas básicas. Essa definição vem da conceituação de ácido / base de Lewis [3], onde o nitrogênio e seus compostos, pôr serem doadores de elétrons, seriam classificados como bases. Com o par de elétrons não compartilhados, a amônia reage com ácidos como doadoras de elétrons, ou, como receptores de prótons para formar sais.

Os termos amina primária, secundária e terciária se referem à quantidade de átomos hidrogênio da amônia que foram substituídos por grupos alquil (GA ou R). Os exemplos a 
seguir ilustram essa definição. A estrutura dos grupos $\mathrm{R}$ é irrelevante como parte da exemplificação [4].<smiles>N</smiles>

Amônia<smiles>[R]N[R]</smiles>

Amina secundária<smiles>[R]N([R])[R]</smiles>

Amina terciária<smiles>[R]N</smiles>

Amina primária<smiles>[R][N+]([R])([R])C</smiles>

Quaternário de amônio

Grande parte das propriedades das aminas graxas advém das características de suas cadeias carbônicas, que são encontradas nos óleos e gorduras sob a forma de triglicérides cuja estrutura é mostrada na figura 1.<smiles>[R]C(=O)OCC(COC([R])=O)OC([R])=O</smiles>

Figura 1: Estrutura de um triglicéride.

Nestes compostos, os radicais R, R' e R' pode denotar cadeias carbônicas de distintos comprimentos e com graus de saturação diferentes, podendo ser uma igual à outra, ou mesmo todas diferentes entre si [5]. A tabela 1 mostra a distribuição típica das cadeias e a nomenclatura comumente usada nos processos de síntese de coletores amínicos.

Atualmente, os ácidos graxos são produzidos por processos contínuos, também denominados "Colgate-Emery". Nesse processo, o ácido graxo e a glicerina são separados de maneira contínua, com água adicionada no topo de um reator com aquecimento e pressão. O óleo é alimentado pela parte inferior e reage com a água num fluxo em contra corrente [6]. A cisão entre o ácido e a glicerina é uma reação de hidrólise e pode ser ilustrada na reação química 1 . $\mathrm{O}$ grupo $\mathrm{RCOOH}$ representa o ácido graxo final liberado pela hidrólise.

Os álcoois graxos podem ser produzidos por um processo de cisão semelhante àquele utilizado na obtenção de ácidos graxos, porém utilizando metanol $\left(\mathrm{CH}_{3} \mathrm{OH}\right)$ ou soda $(\mathrm{NaOH})$ ao invés de água. A reação é denominada intertroca de ésteres e cujo resultado é um éster metílico do ácido graxo correspondente e glicerina. Posteriormente o éster é hidrogenado para a obtenção final do álcool. 
Tabela 1: Composições de cadeias para distintos óleos e gorduras - \% peso [7].

\begin{tabular}{|l|c|c|c|c|c|c|c|c|}
\hline Cadeia & $\begin{array}{l}\text { Carbonos } \\
\text { na cadeia }\end{array}$ & $\begin{array}{l}\text { Duplas } \\
\text { Ligações }\end{array}$ & Côco & Palma & $\begin{array}{l}\text { Semente } \\
\text { de } \\
\text { Palma }\end{array}$ & $\begin{array}{l}\text { Soja } \\
\text { Animal }\end{array}$ & $\begin{array}{l}\text { Sebo Tall” } \\
\text { Oil" }\end{array}$ \\
\hline Capróico & 6 & 0 & 0,5 & - & - & - & - & - \\
\hline Caprílico & 8 & 0 & 7 & - & 3,5 & - & - & - \\
\hline Cáprico & 10 & 0 & 6 & - & 3,5 & - & - & - \\
\hline Láurico & 12 & 0 & 48 & - & 48,8 & - & - & - \\
\hline Mirístico & 14 & 0 & 19 & 2 & 16,6 & - & 3,5 & - \\
\hline Miristolênico & 14 & 1 & - & - & - & - & 1 & - \\
\hline Pentadecanóico & 15 & 0 & - & - & - & - & 0,5 & - \\
\hline Palmítico & 16 & 0 & 9 & 42 & 8,5 & 11 & 25,3 & 1 \\
\hline Palmitoléico & 16 & 1 & - & - & - & - & 4 & 0,5 \\
\hline Margárico & 17 & 0 & - & - & - & - & 2,5 & - \\
\hline Esteárico & 18 & 0 & 3 & 4 & 2,5 & 4 & 19,4 & 1,5 \\
\hline Oléico & 18 & 1 & 6 & 43 & 14,6 & 21 & 40,8 & 50,5 \\
\hline Linoléico & 18 & 2 & 1,5 & 9 & 2 & 55,5 & 2,5 & 46,5 \\
\hline Linolênico & 18 & 3 & - & - & - & 8,5 & - & - \\
\hline Araquídico & 20 & 0 & - & - & - & - & 0,5 & - \\
\hline
\end{tabular}

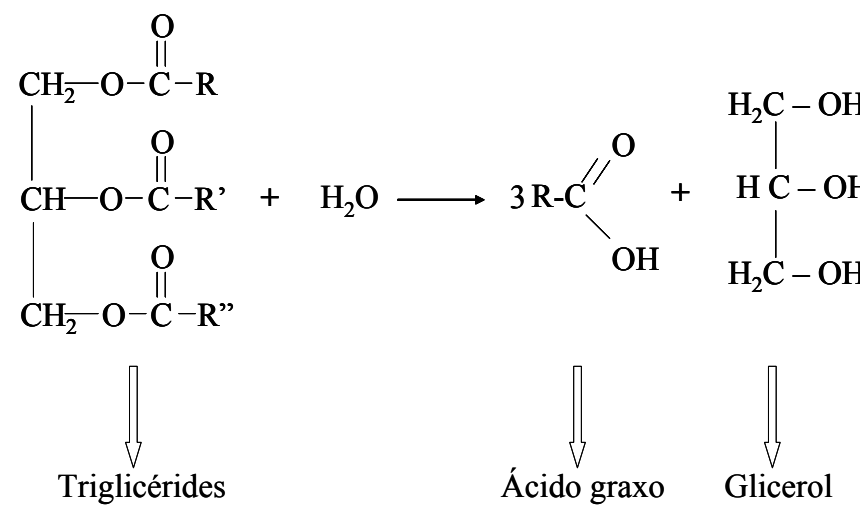

A partir da obtenção dos ácidos e álcoois graxos, torna-se possível à produção de vários tipos de aminas, que, por sua vez, também poderão tomar parte em processos de obtenção de outros derivados nitrogenados. A figura 2 sintetiza rotas de produção das aminas e seus derivados utilizados como coletores em mineração.

Problemas na composição ou na qualidade dos coletores podem ser gerados por falhas nos processos de produção ou na matéria prima que os origina. O engenheiro tratamentista não possui, via de regra, controle algum sobre os processos de fabricação dos produtos químicos consumidos na usina de concentração, mas pode fazer uso de procedimentos e dados analíticos para certificar-se de que os coletores que utiliza estão dentro de certas especificações que asseguram sua composição, qualidade e desempenho. Na tabela 2, são apresentados os métodos analíticos mais importantes utilizados para caracterizar uma amina. 


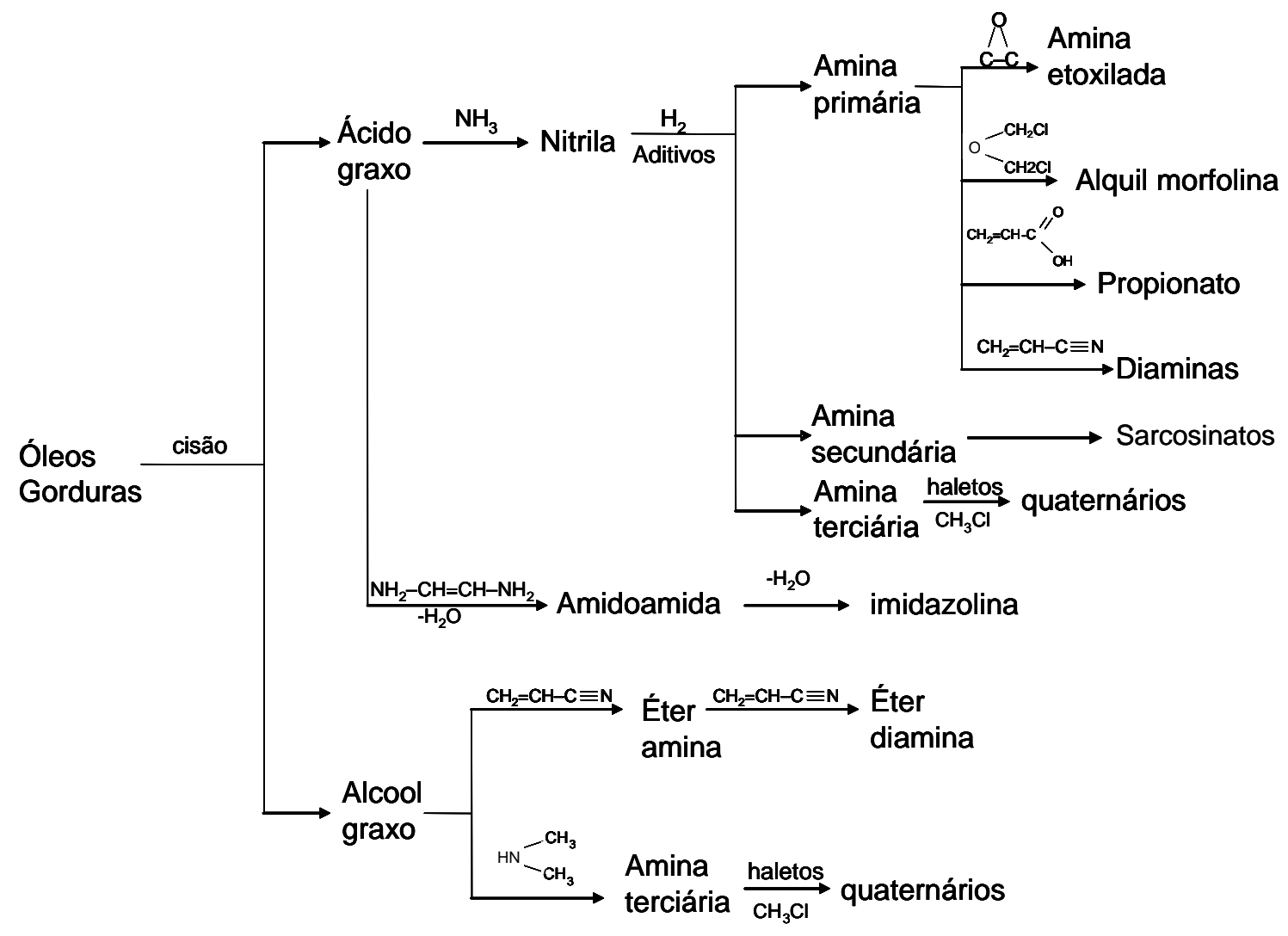

Figura 2: Fluxograma com o resumo das rotas de produção das aminas e seus derivados.

Tabela 2: Métodos de análise de aminas e derivados [8;9].

\begin{tabular}{|l|c|c|}
\hline \multicolumn{1}{|c|}{ Método } & AOCS & ASTM $^{4}$ \\
\hline Índice de amina & Tf 1A / 1B-64 & D 2073 e D 2074 \\
\hline Índice de Iodo & $\begin{array}{c}\text { Tg 2A-64 para aminas e } \\
\text { Tg 3A para quaternários }\end{array}$ & $\begin{array}{l}\text { D 2075 } \\
\text { D 2078 }\end{array}$ \\
\hline Índice de neutralização e de acidez & Te 1A-64 & D 1980 \\
\hline Ponto de fusão & Cc 3B-92 & - \\
\hline Ponto de turvação & Cc 6-25 & - \\
\hline Inflamabilidade (flash point) & Tn 1A & D 92 \\
\hline
\end{tabular}

\section{1 Índice de amina ( IA ) [10;11]}

A determinação do IA é uma forma de expressar o teor de amina presente em uma certa amostra. Levando-se em conta que as aminas apresentam características básicas, o valor de IA é obtido através da titulação de uma massa definida desse composto com uma solução de um ácido forte ( ácido clorídrico ou perclórico). Nessa operação determina-se a

\footnotetext{
${ }^{1}$ AOCS é a sigla para "American Oil Chemists Society".

${ }^{2}$ ASTM é a sigla para "American Society for Testing Materials".
} 
quantidade de ácido necessária para neutralizar um grama do derivados de amina, cuja grandeza é expressa em $\mathrm{mg} \mathrm{KOH} / \mathrm{g}$. Para exemplificar suponha uma amostra de amina de 1,0 grama que foi titulada com solução de ácido clorídrico $0,2 \mathrm{M}$. O volume de ácido gasto foi de $19,15 \mathrm{ml}$.

$\mathrm{IA}=\left(\frac{\mathrm{V}_{(\mathrm{ml})} \cdot \mathrm{M}}{\mathrm{m}_{(\mathrm{g})}}\right) \cdot \mathrm{MOL} \mathrm{KOH} \quad \mathrm{IA}=\left(\frac{19,15 \cdot 0,2}{1,0}\right) \cdot 56,1 \quad \rightarrow \quad \mathrm{IA}=214,9 \mathrm{mgKOH} / \mathrm{g}$

Portanto, dependendo da origem da amina, podem ser estabelecidas faixas de especificação para o IA. Isso posto, algumas interpretações em relação aos valores de IA podem ser assumidas. Um valor de IA muito baixo indicará a presença de outros produtos que não as aminas e que podem ser subprodutos gerados em alguma etapa durante o processo de síntese. Valores de IA baixos para aminas primárias ou eteraminas, podem indicar a presença de nitrilas não hidrogenadas no caso do primeiro, ou eternitrilas ou álcool graxo e acrilonitrila livres, quando se tratar de eteraminas.

\section{2 Índice de neutralização ( IN) e Índice de acidez ( IAc) [10;11]}

As aminas e seus derivados são, em geral, insolúveis em água e suas propriedades catiônicas somente se expressarão quando esses compostos puderem se ionizar em meio aquoso. Por isso, as aminas são geralmente comercializadas na forma de sais.

Assim como o IA, o IAc, é uma forma de expressar o teor de ácido presente na amostra de derivado de amina, após sua neutralização. Sua determinação acontece de forma análoga ao IA. A diferença é que a amostra de derivado de amina neutralizada, é titulada com uma solução de base forte, como o hidróxido de sódio ou de potássio, onde se determina a quantidade de base necessária para neutralizar o ácido presente em um grama de amostra, cuja grandeza também é expressa em $\mathrm{mg} \mathrm{KOH} / \mathrm{g}$. A mesma exemplificação feita em 2.1 também pode ser realizada no IAc e os cálculos são realizados de maneira análoga. Portanto, a amostra de 1,0 grama de amina neutralizada, titulada com solução de hidróxido de sódio $0,2 \mathrm{M}$, cujo volume gasto da solução de ácido clorídrico foi de $15,33 \mathrm{ml}$, fornece um IAc de $172 \mathrm{mgKOH} / \mathrm{g}$.

O índice de neutralização é expresso através da relação entre o índice acidez dividido pelo índice de aminas e fornece um número que multiplicado por 100 indicará a porcentagem de neutralização da amostra.

Considerando os exemplos anteriores utilizados na determinação do IA e IAc, o IN é ilustrado a seguir:

$$
\mathrm{IN}=\frac{172,0}{214,9} \cdot 100=80,0 \%
$$

Industrialmente se usam produtos com graus de neutralização que variam entre $30 \%$ e $100 \%$. O conhecimento desses valores é particularmente importante porque as frações que não estiverem na forma de sais tenderão a se comportar como tensoativos não iônicos tendo uma enorme influência na formação do filme hidrofóbico que se forma na superfície das partículas de minério. 


\subsection{Ponto de turvação (cloud point) e ponto de claridade (clear point )}

O ponto de turvação é a temperatura na qual um líquido começa a exibir sinais de turvação, ou precipitação visível durante o resfriamento.

Em geral, o ponto de turvação é determinado pelo resfriamento de uma dada amostra fazendo-se a observação da temperatura na qual surgem os primeiros sinais de turvação ou precipitação. Essa determinação é normalmente feita com o produto tal qual, podendo também ser feita com uma diluição aquosa ou em um solvente específico.

O ponto de claridade refere-se à situação oposta a ponto de turvação, sendo a temperatura na qual um produto turvo se torna claro, ou quando desaparece a turvação.

Esses dois parâmetros são importantes de serem avaliados pelo engenheiro tratamentista porque a turvação de uma solução contendo um coletor ou qualquer outro reagente mostra a existência de duas fases, caracterizando que não existe uma completa dissolução do composto químico no meio aquoso.

\section{4 Índice de iodo ( IV ) [10;11]}

O índice de iodo é usado para expressar o grau de insaturação de uma variedade de produtos. Ele é definido como a quantidade de iodo consumido na titulação de 100 gramas de uma dada amostra. Cada dupla ligação contida na cadeia do hidrocarboneto irá reagir com um mol de iodo. Para determinar o IV, uma amostra padrão de material é reagida com excesso de iodo sendo que esse excesso é medido por titulação com tiosulfato de sódio. Quanto maior o índice de iodo maior será o grau de insaturação da cadeia hidrocarbônica do coletor.

Uma amina oléica, por exemplo, tem um IV $\sim 90 \mathrm{cg}$ I / grama enquanto que uma amina esteárica, tipo octadecilamina, esse valor é $<3 \mathrm{cg} \mathrm{I} / \mathrm{g}$ [10]. Observando-se a tabela 1 pode-se notar que o ácido oléico apresenta uma insaturação enquanto a esteárica é totalmente saturada ${ }^{3}$, comprovando a diferença entre esses valores.

\subsection{Ponto de fusão, temperatura de amolecimento e "Pour Point"}

O ponto de fusão é simplesmente interpretado como a temperatura na qual um sólido funde. É muito comum que os derivados nitrogenados não tenham um ponto de fusão definido, mas sim uma faixa de temperatura na qual isso ocorra. Esse efeito acontece porque quase sempre existem misturas de cadeias carbônicas presentes em um mesmo produto. Como cada cadeia tem seu ponto de fusão definido, em geral diferente das demais, passa a fazer sentido o conceito de faixa de fusão. A figura 3 descreve o comportamento do ponto de fusão de aminas primárias de cadeias pares e impares e também dos seus respectivos sais na forma de acetatos. Interessante notar que o ponto de fusão dos sais são bastante mais elevados que das aminas não neutralizadas [12].

\footnotetext{
${ }^{3}$ Se as aminas fossem $100 \%$ saturadas o IV seria zero e não $<3$ como citado. Industrialmente não se consegue obter produtos com pureza de 100 \% gerando essa pequena discrepância de valores.
} 


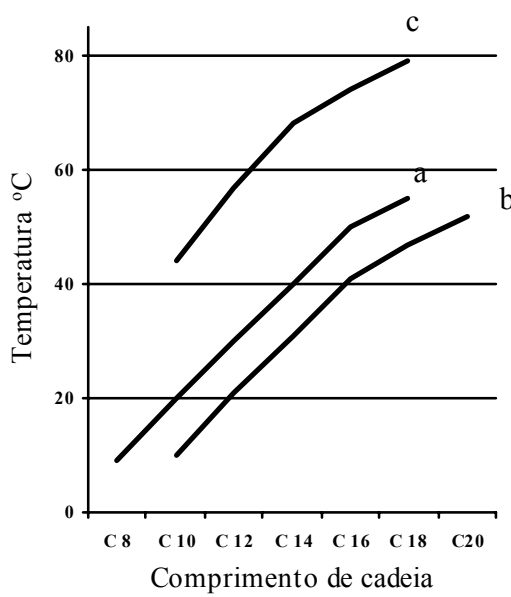

Figura 3: Temperaturas aproximadas de fusão de aminas primárias lineares: (a) pares; (b) ímpares e (c) seus respectivos acetatos [12].

O "pour point" ou ponto de escorrimento é definido como sendo a menor temperatura na qual um líquido deverá escorrer ou fluir. Para o engenheiro tratamentista essa propriedade estará relacionada ao conceito de manuseiabilidade do produto.

A determinação dessas propriedades é de grande relevância àqueles que manuseiam produtos químicos. Dependendo da região no Brasil as amplitudes térmicas podem ser significativas e problemas como a solidificação de reagentes pode se tornar uma realidade em certas épocas do ano.

\subsection{Temperatura de inflamabilidade (flash point)}

Trata-se de um valor de temperatura em que um composto, líquido ou sólido volátil, desprende vapor em quantidade suficiente para formar uma mistura inflamável com o ar próximo à superfície do composto ou dentro da embalagem que o encerra [11].

Essa medida é de particular importância quando se trabalha com sais de amônio quaternário que podem conter isopropanol ou etanol como solventes.

O conhecimento do "flash point" é acima de tudo uma condição de segurança para aqueles que trabalham com produtos químicos.

\section{AS AMINAS COMO TENSOATIVOS E SUAS PROPRIEDADES}

Segundo o "Surfactants in consumer products" [12], os tensoativos são substâncias com estrutura molecular que possuem uma parte hidrofílica (afinidade com água) e uma porção hidrofóbica (aversão à água), sendo que a primeira é normalmente composta por um hidrocarboneto e a segunda por uma parte iônica ou polar, classicamente descrita pela figura 4 .

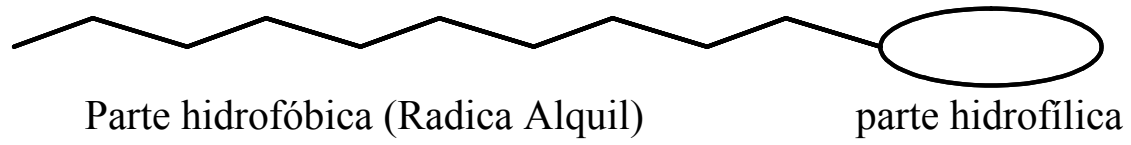

Figura 4: Esquema de um tensoativo segundo o "Surfactants in Consumers Products" mostrando a parte polar (hidrofílica) e a parte apolar (hidrofóbica) [13]. 
A carga elétrica que compõe a parte hidrofílica e as inúmeras variações dos tipos de cadeias carbônicas que podem compor a parte hidrofóbica, permitem que se tenham um grande número de combinações gerando produtos distintos e com propriedades únicas. Por conta disso, os tensoativos podem ser classificados de diversas formas. A mais usual e clássica agrupa os produtos enquanto sua carga iônica, dividindo-os em catiônicos (positivo), aniônicos (negativo), não iônicos (sem carga) e anfotéricos (positivos em pH ácido e negativo em $\mathrm{pH}$ alcalino).

\section{1 - Tensão Superficial e CMC}

Para definir o conceito de tensão superficial considere-se um líquido em equilíbrio com seu vapor conforme ilustrado na figura 5. Uma molécula no interior do líquido é solicitada radialmente pelas forças de atração das moléculas vizinhas de modo que estas forças estejam perfeitamente balanceadas e cujo somatório seja zero. Na superfície, entretanto, a atração intermolecular gera uma resultante não nula porque que o hemisfério inferior está preenchido totalmente com moléculas que a atraem, e o hemisfério superior, por se estender além da superfície do líquido, está preenchido apenas parcialmente com moléculas que a atraem.

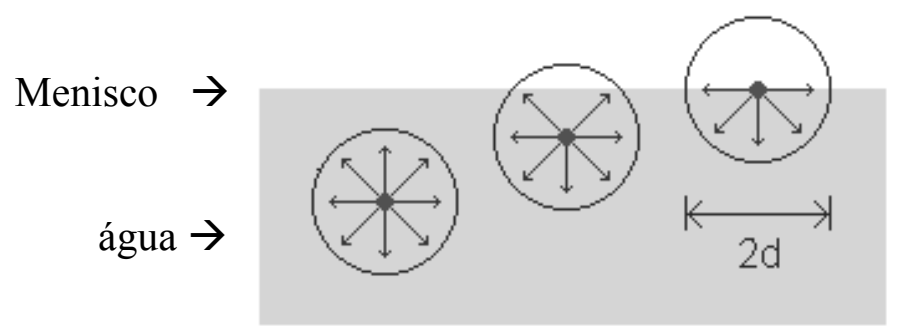

Figura 5: Balanço de forças na interface e no seio de um líquido. A resultante de forças no interior do líquido é zero enquanto que na superfície elas são a metade daquelas no interior da solução.

$\mathrm{Na}$ fronteira líquido - ar, o desbalanceamento das forças é máximo, existindo uma forte tendência das moléculas que se encontram dentro de uma camada superficial serem puxadas para o interior do líquido havendo uma contração espontânea da superfície nesta direção. Por outro lado, as moléculas da camada superficial estarão se movendo também para o interior do líquido, aumentando a superfície à medida que um trabalho positivo é realizado. Dessa forma, a superfície de um líquido pode ser aumentada ou diminuída à medida que se realiza trabalho e um certo número de moléculas passa do interior do líquido para a camada superficial. Dessa relação de variação de área superficial se obtém o coeficiente de tensão superficial $(\gamma)$, cujos valores para algumas substâncias são apresentados na tabela 3 .

Tabela 3: Valores de $\gamma$ de diversos líquidos, à temperatura de $25^{\circ} \mathrm{C}$, [14].

\begin{tabular}{|l|c|}
\hline Tipo do líquido & $\begin{array}{c}\text { Tensão Superficial } \\
\text { dynas } / \mathbf{c m}\end{array}$ \\
\hline Água & 72,6 \\
\hline Fluorcarbonos & $8-15$ \\
\hline Hidrocarbonetos & $18-30$ \\
\hline Orgânicos polares & $22-50$ \\
\hline Soluções detergentes & $24-40$ \\
\hline
\end{tabular}


De acordo com a tabela 3, a tensão superficial da água é de aproximadamente $72 \mathrm{dyn} / \mathrm{cm}$, sendo que esse valor é reduzido quando se introduz algum tensoativo. A razão desse efeito é ilustrado na figura 6. O ponto de estabilidade do sistema é atingido quando a molécula se posiciona na interface de duas fases (combinando a parte lipofílica com a fase oleosa e a parte hidrofílica com a água).

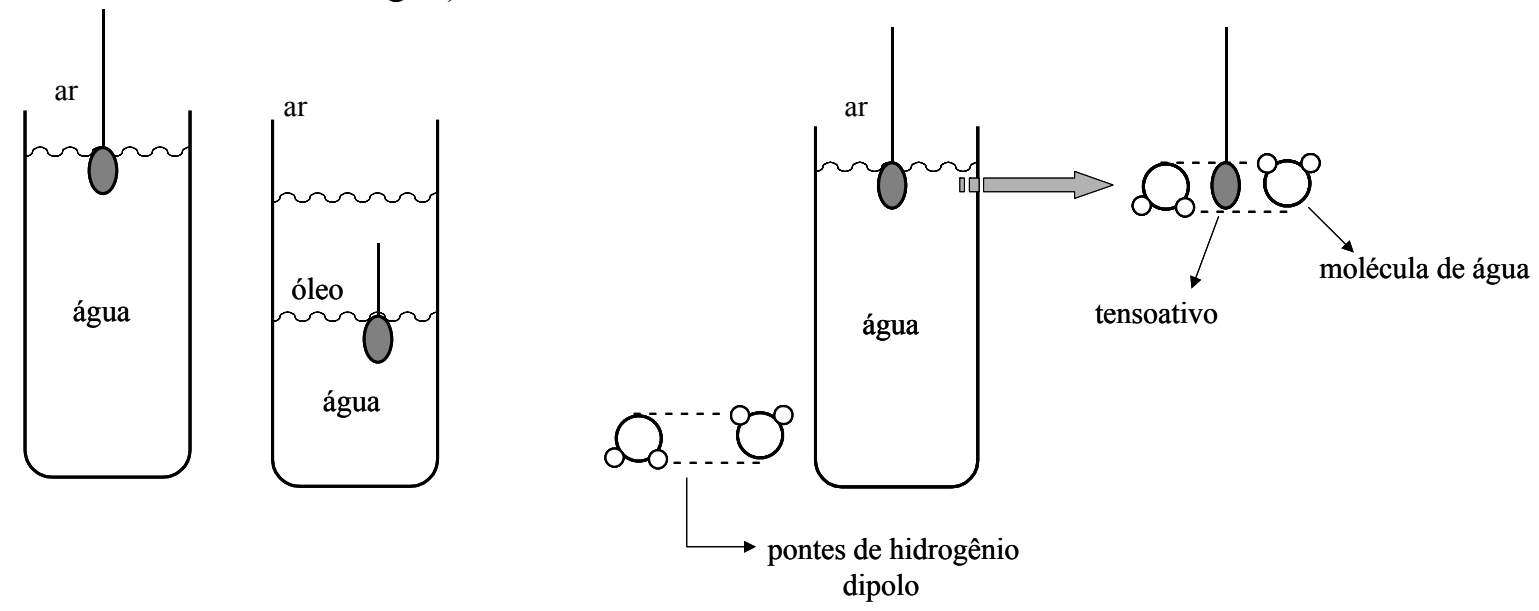

Figura 6: Posicionamento dos tensoativos na interface de um sistema bifásico (ar-água) e multifásico (ar-água-óleo) e efeito da adição de tensoativos na redução da tensão superficial da água.

A "American Chemical Association" [15] tem vários ábacos com os valores de $\gamma$ para diferentes tipos de n-alquilaminas, cujos valores estão ilustrados na figura 7.

Uma característica dos coletores catiônicos é a capacidade de formar agregados em solução aquosa a partir de uma determinada concentração. Estes agregados são denominados micelas. A concentração onde se inicia o processo de formação dessas estruturas (micelização) é chamada de concentração micelar crítica, ou simplesmente $\mathrm{CMC}$, que é uma propriedade intrínseca e característica do produto.

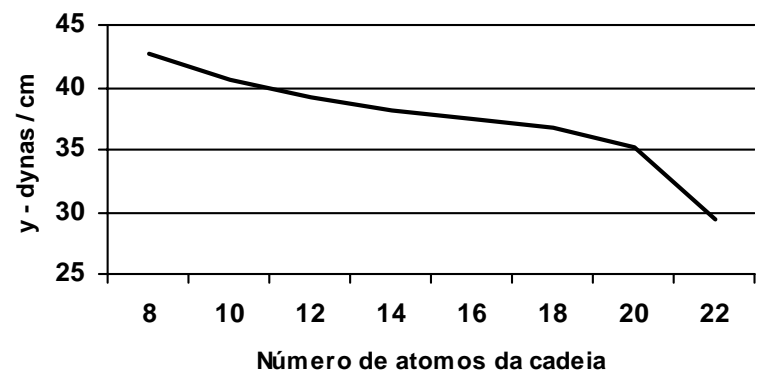

Figura 7: Tensão superficial de $\mathrm{N}$-alquil aminas, com grupos alquil variando de C8 a C22. Dados obtidos a $20{ }^{\circ} \mathrm{C}[17]$.

Quando tensoativos são adicionados à água, as propriedades de redução de tensão superficial atingem um valor mínimo a partir do qual se estabiliza mesmo quando mais tensoativo é adicionado. Esse efeito ocorre porque as moléculas terão atingido sua saturação na interface líquido - ar [16].

A geometria das micelas pode variar de acordo com os tipos de tensoativos e de acordo com o meio no qual estão solubilizados. Como regra geral, os tensoativos formam micelas quase esféricas de raio praticamente equivalente ao do comprimento do radical 
hidrocarbônico [17] sendo que micelas com outras geometrias (cilíndricas ou placas) também são possíveis de ser formadas [18].

A figura 8 mostra o efeito da redução da tensão superficial versus a quantidade de tensoativos. O ponto de inflexão da curva é denominado de CMC.

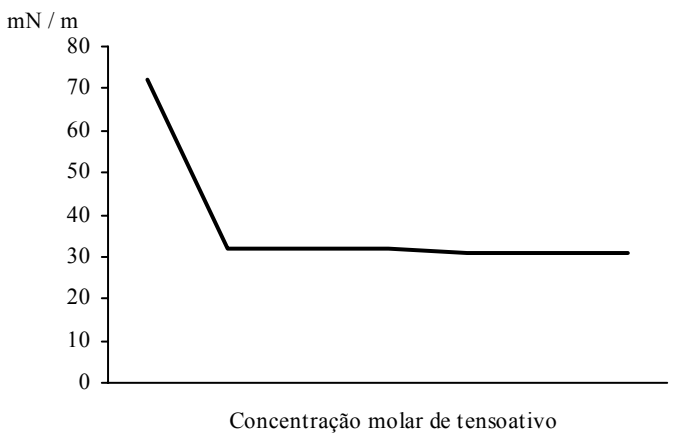

Figura 8: Curva típica de tensão superficial $x$ quantidade de tensoativo. O ponto de inflexão da curva é definido como o CMC.

Para os coletores catiônicos, como regra geral, o valor de $\mathrm{CMC}$ diminui à medida que aumenta o tamanho da cadeia carbônica, sendo que a presença de eletrólitos também faz com que a CMC seja reduzida. O conceito de CMC é bastante importante nos processos de flotação. Quando se utilizam quantidades de coletores muito abaixo da CMC pode-se esperar um fraco resultado de recuperação por não haver tensoativo suficiente para aderir na superfície do mineral e ligar-se à bolha. Por outro lado, um excesso de coletor pode induzir à formação de micelas aprisionando os coletores. Na tabela 4 são fornecidos alguns valores de CMC para vários tipos de aminas.

Tabela 4: Concentração micelar crítica de alguns derivados de aminas $[20 ; 19]$

\begin{tabular}{|l|c|l|c|}
\hline Tipos de aminas & CMC - mol / & Tipos de aminas & CMC - mol / \\
\hline Decilamina & $3,2 \times 10^{-2}$ & Octadecilamina & $1,9 \times 10^{-3}$ \\
\hline Dodecilamina & $1,3 \times 10^{-2}$ & $\begin{array}{l}\text { Brometo de dimetil di- } \\
\text { dodecil amônio }\end{array}$ & $1,8 \times 10^{-4}$ \\
\hline Tetradecilamina & $4,1 \times 10^{-3}$ & $\begin{array}{l}\text { Brometo de trimetil } \\
\text { dodecil amônio }\end{array}$ & $1,75 \times 10^{-2}$ \\
\hline Hexadecilamina & $0,8 \times 10^{-3}$ & $\begin{array}{l}\text { Propionato de } \\
\text { dodecilamina }\end{array}$ & $1,65 \times 10^{-3}$ \\
\hline
\end{tabular}

WALTSON e MANSER [20] observaram que próximas a CMC as aminas primárias, tipo dodecilamina, simplesmente perdem sua propriedades de flotar silicatos devido aos fatores comentados anteriormente e, portanto, a otimização da quantidade de tensoativos é uma das chaves para o sucesso do processo de flotação.

\section{2 - Ponto Kraft (PK) e Solubilidade}

O ponto Kraft (PK), é definido como sendo a temperatura acima da qual ocorre uma abrupta mudança na solubilidade de um tensoativo, ilustrado na figura 9. A solubilidade das aminas está relacionada ao tamanho, tipo de grupo funcional, número e saturação de cadeias carbônicas. Como regra geral, pode-se dizer que os compostos de cadeia linear são 
menos solúveis em água que seus pares ramificados com equivalente número de carbonos na cadeia. A solubilidade aumenta com o aumento de grupos funcionais, hidroxilas, por exemplo, e com as insaturações. Quanto mais longo é o grupo lipofílico menor será a solubilidade em água.

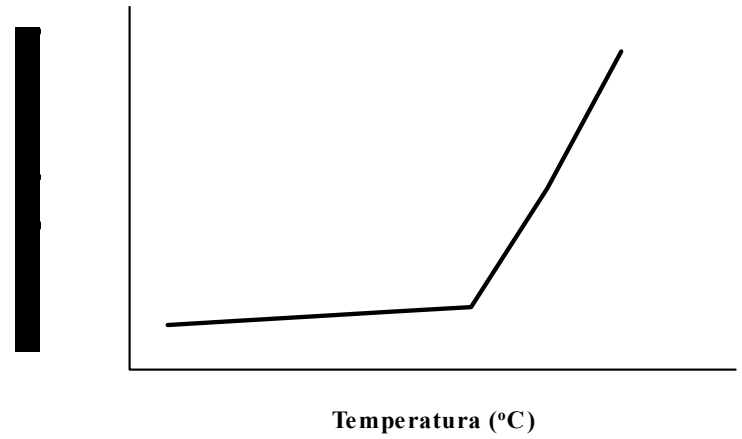

Figura 9: Comportamento típico de surfactantes catiônicos e não iônicos mostrando a variação da solubilidade x temperatura. A inflexão da curva é chamada de ponto Kraft.

Como a solubilidade dos coletores sofre grande variação em uma faixa de temperatura estreita (menor que $5^{\circ}$ ), deve-se sugerir que os engenheiros tratamentistas busquem informações sobre tal propriedade com relação ao coletor que está sendo usado e tenham o cuidado de avaliar a temperatura de seu processo de flotação ao longo do tempo, visando compreender as possíveis variações na temperatura da polpa e sua influência no desempenho dos reagentes de flotação.

O conhecimento das propriedades de solubilização dos derivados de amina é importante porque grande parte dos coletores catiônicos usados apresenta seu ponto Kraft próximo à temperatura ambiente, ou seja entre $25^{\circ}$ e $30^{\circ}$. Nas minas de silvita do Canadá, é comum que se use um tipo de coletor no verão, normalmente de cadeia $\mathrm{C} 18 / \mathrm{C} 22$ enquanto que no inverno, é muito usual utilizar uma amina de sebo, que tem cadeias mais curtas. Esse é um bom exemplo de como utilizar a informação do ponto Kraft.

\section{3 - HLB}

HLB é a sigla das palavras inglesas "Hydrophilic - Lipophilic - Balance" ou seja, é a designação entre o balanço hidrofílico e lipofílico dos tensoativos. É de se esperar que em um tensoativo uma das partes descritas acima seja mais preponderante em relação a outra. SHINODA e FRIBERG [21], descrevem diversos autores que matematicamente determinaram esses índices, sendo que os valores obtidos por Griffin, e Davies são os mais usados. Cada metodologia é obtida de forma empírica e como resultado pode-se concluir um valor de HLB baixo indica que a parte hidrofóbica está dominando enquanto que o HLB alto indica que a parte hidrofílica é dominante.

\section{4 - Biodegradabilidade, Toxicidade e Manuseio.}

A preocupação com o impacto ambiental das atividades de mineração sempre foi um tema bastante debatido pela indústria. $\mathrm{O}$ uso de produtos químicos em processos de flotação se insere nesse contexto porque a maior parte dos compostos usados na etapa de concentração acaba, de alguma forma, sendo carreados para uma unidade de tratamento ou para as barragens de rejeitos. 
Os três testes mais comuns de serem realizados para determinar a biodegradabilidade de produtos químicos são: Biodegradabilidade imediata ou rápida (readly), biodegradabilidade natural (inherently) e testes de simulação (simulation tests).

A biodegradabilidade rápida é comumente usada para fins regulatórios porque ela define com clareza os riscos de uma substância. Nesse teste a biodegradação é monitorada através da medição do consumo de oxigênio ou pela produção de dióxido de carbono durante um período de 28 dias em um teste chamado garrafa fechada (closed bottle test). O produto que se deseja avaliar é fechado em uma garrafa com uma solução de água e microorganismos onde são monitorados constantemente o oxigênio e/ou o dióxido de carbono. $\mathrm{O}$ resultado da avaliação é expresso como a $\%$ de $\mathrm{CO}_{2}$ formado em relação ao teórico ou pela relação entre o consumo biológico de $\mathrm{O}_{2}$ versus a demanda teórica desse composto. Um resultado positivo nesse teste indica que a substância é degradada rapidamente. Entretanto, os resultados de biodegradabilidade imediata tendem a subestimar o potencial de biodegradação com relação ao ambiente. Quando o resultado desse teste é negativo ou dúbio, a avaliação da biodegradabilidade natural ou os testes de simulação são usados como uma certificação [22].

Quase todas aminas podem ser consideradas rapidamente biodegradáveis. Os dados apresentados na tabela 5 mostram uma série de derivados de aminas e suas respectivas classificações com relação a biodegradação.

Tabela 5: Classificação da biodegradação de vários compostos catiônicos com seus respectivos radicais hidrofóbicos e hidrofílicos [24].

\begin{tabular}{|l|l|l|}
\hline Composto Catiônico & $\begin{array}{l}\text { Cadeia carbônica } \\
\text { (Radical Alquil })\end{array}$ & "Moieties" \\
\hline Sal de alquil trimetil amônio $\left(\mathrm{C}_{10}-\mathrm{C}_{18}\right)$ & Rapidamente & Rapidamente \\
\hline Sal de dialquil dimetil amônio $\left(\mathrm{C}_{10}-\mathrm{C}_{12}\right)$ & Rapidamente & Rapidamente \\
\hline Polioxietileno alquil amina 4EO $\left(\mathrm{C}_{12}\right)$ & Rapidamente & Natural \\
\hline Alquil dimetil aminas $\left(\mathrm{C}_{12}-\mathrm{C}_{18}\right)$ & Rapidamente & Rapidamente \\
\hline Sal de alcoxi propano amina $\left(\mathrm{C}_{10}-\mathrm{C}_{13}\right)$ & Rapidamente & Rapidamente \\
\hline Acetato de alquil amina primária $\left(\mathrm{C}_{12}-\mathrm{C}_{18}\right)$ & Rapidamente & Rapidamente \\
\hline Acetato de alquil, 1-3 propano amina $\left(\mathrm{C}_{12}-\mathrm{C}_{18}\right)$ & Rapidamente & Rapidamente \\
\hline
\end{tabular}

Praticamente todos os derivados de aminas são classificados como perigosos e seu manuseio deve ser feito com toda a segurança possível. Em geral eles são irritantes aos olhos e à pele. Emitem vapores amoniacais e se inalados, podem causar náusea ou vômitos e cuidados específicos devem ser tomados em caso de ingestão acidental. Sempre se recomenda que os usuários de produtos químicos leiam as informações contidas nas FISPQ $^{4}$ que por força de lei devem acompanhar os produtos desde sua origem até seu

\footnotetext{
${ }^{4}$ FISPQ - Ficha de informação de segurança de produtos químicos. De acordo com as normas do programa de atuação responsável da Associação Brasileira da Indústria Química - ABIQUIM, esse documento deve sempre acompanhar os produtos químicos e têm que conter todas as informações sobre procedimentos de emergência em caso de incidentes.
} 
destino. Todo e qualquer manuseio de produtos químicos deve ser feito com o uso dos $\mathrm{EPI}^{5}$ apropriados.

\section{MECANISMOS DE ATUAÇÃO DAS AMINAS NOS PROCESSOS DE FLOTAÇÃO}

Os minerais, com algumas exceções ${ }^{6}$, são facilmente molháveis pela água, sendo, portanto, hidrofílicos por natureza. Os óxidos e silicatos requerem coletores que sejam ionicamente fortes e que tenham grandes grupos hidrofóbicos (baixo HLB). Esses dois requisitos são atingidos quando se usa um tipo de coletor que tenha em sua estrutura uma cadeia carbônica proporcionalmente mais longa que a do grupo iônico e que deve se ionizar com facilidade. Os derivados de aminas graxas preenchem esses requisitos e por isso seu uso é tão difundido em processos de flotação de óxidos, silicatos e outros minerais hidrofílicos.

Sendo a flotação um processo que explora as diferenças entre a hidrofilicidade e hidrofobicidade das partículas minerais, é necessário que o coletor transforme o caráter naturalmente hidrofílico das partículas, reduzindo sua energia livre interfacial e formando um ângulo de contato maior que zero. Para que as aminas e outros derivados nitrogenados exerçam tal papel, é necessário que as mesmas se concentrem na interface mineral/solução (adsorção positiva). Como decorrência desse fenômeno, tem-se que o ângulo de contato $(\theta)$ será favorável a flotação $(\theta>0)$.

A natureza do adsorvente, ou seja, o tipo de mineral que será o adsorvato para as aminas, determinará o mecanismo pelo qual essas espécies químicas irão se adsorver na interface mineral/solução:

i. Quando os minerais forem da família dos óxidos, silicatos (oximinerais) e sais semi-solúveis, a literatura [23] indica que as propriedades elétricas interfaciais, como o potencial zeta (PZ), dos minerais governam o processo de adsorção.

i.i. quando os minerais pertencem à família dos sais solúveis ${ }^{7}$, a natureza da água interfacial, assim como a capacidade dos derivados de aminas de formar pontes de hidrogênio com sítios da interface, controlam o mecanismo de adsorção [24].

\section{1 - Flotação de oximinerais com aminas e seus derivados}

A literatura [25;25] fornece evidências que as aminas e seus derivados adsorvem na interface mineral/solução através de dois mecanismos:

i. Atração eletrostática entre a superfície negativa do mineral e o grupo funcional positivo. Dessa forma, as moléculas deverão atuar como contra-íons na interface. Para que seja possível um arranjo molecular bidimensional compacto, é necessário que existam aminas na sua forma neutra, que estarão se posicionando entre as espécies carregadas formando um arranjo tipo "sanduíche".

i.i. Interações intermoleculares laterais entre as cadeias hidrocarbônicas e que são governadas por forças de Van der Walls. Tais interações visam compactar ainda mais o filme hidrofóbico que será formado na interface da partícula do mineral.

\footnotetext{
${ }^{5}$ EPI - Equipamento de proteção individual

${ }_{7}^{6}$ Algumas das exceções são o talco, grafite, carvão, pirofilita, enxofre, molibdenita dentre outros.

${ }^{7}$ Silvita ( $\mathrm{KCl}$ ), carnalita $\left(\mathrm{KCl} \cdot \mathrm{MgCl}_{2} \cdot 6 \mathrm{H}_{2} \mathrm{O}\right)$, schoenita $\left(\mathrm{K}_{2} \mathrm{SO}_{4} \cdot \mathrm{MgSO}_{4} \cdot 6 \mathrm{H}_{2} \mathrm{O}\right)$, etc.
} 
Para que ocorra a adsorção das aminas por atração eletrostática é necessário que o $\mathrm{pH}$ da suspensão seja maior que o $\mathrm{pH}$ onde o PZ é zero ( $>$ IEP). A tabela 6 indica o $\mathrm{pH}$ onde ocorre o PZC (ponto de zero carga) de diversos oximinerais. Assumindo que o PZC e o IEP são valores muito próximos, a interpretação dos dados dessa tabela, indicam que para valores de $\mathrm{pH}$ menores que do $\mathrm{PZC}$, a carga superficial será positiva enquanto para valores de $\mathrm{pH}$ maiores a carga será negativa. Faz sentido, portanto, utilizar essa regra para selecionar que tipo de coletor poderá ser usado em uma dada faixa de $\mathrm{pH}$, mas alguns cuidados devem ser tomados na generalização do conceito.

LEAL FILHO [26], sumarizou o PZC em faixas de variação para grupos de minerais como silicatos, óxidos e sais semi-solúveis, com algumas poucas exceções como o quartzo. $\mathrm{O}$ resultado é ilustrado na figura 10.

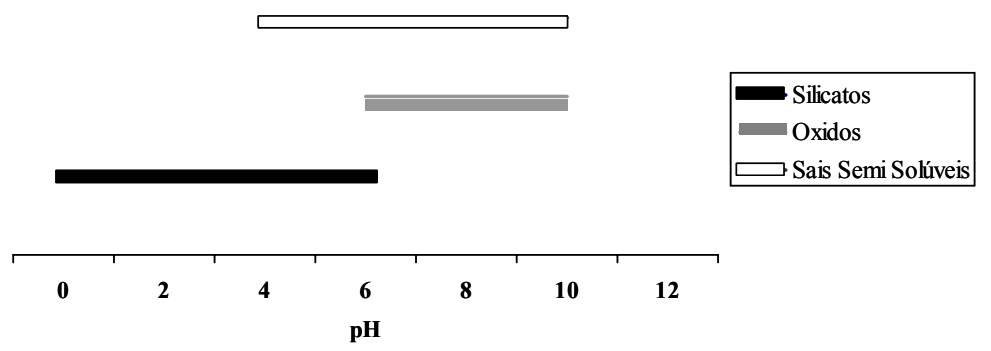

Figura 10: Faixas de pH onde se concentram os pontos de zero carga (PZC) dos principais silicatos, óxidos e sais semi-solúveis [28].

As aminas e seus derivados adsorvem não especificamente e positivamente nas superfícies sendo que o mecanismo de adsorção é governado basicamente pela atração eletrostática entre a superfície do mineral e a carga positiva do grupo funcional.

Tabela 6: Pontos de carga zero (PZC) de alguns óxidos e silicatos [25;27;27]

\begin{tabular}{|l|c|c|}
\hline Óxidos e silicatos & pH - IEP & Referência \\
\hline Quartzo $-\mathrm{SiO}_{2}$ & $2-3$ & $\mathbf{2 6}$ \\
\hline Quartzo $-\mathrm{SiO}_{2}$ & $2,3-3,7$ & $\mathbf{2 8}$ \\
\hline Cassiterita $-\mathrm{SnO}_{2}$ & 4,5 & $\mathbf{2 8}$ \\
\hline Hematita $-\mathrm{Fe}_{2} \mathrm{O}_{3}$ & $4,8-6,7$ & $\mathbf{2 6 ; 2 8}$ \\
\hline Espodumenio $-\mathrm{LiAl}_{2}\left(\mathrm{SiO}_{3}\right)_{2}$ & 2,6 & $\mathbf{2 6}$ \\
\hline Talco $-\mathrm{Mg}_{6}\left(\mathrm{Si}_{8} \mathrm{O}_{20}\right)(\mathrm{OH})_{4}$ & 3,6 & $\mathbf{2 8}$ \\
\hline Ortoclásio $-\mathrm{K}_{(}\left(\mathrm{AlSi}_{3} \mathrm{O}_{8}\right)$ & 1,7 & $\mathbf{3 0}$ \\
\hline Mica $-\mathrm{K}_{2} \mathrm{Al}_{4}\left(\mathrm{Al}_{2} \mathrm{Si}_{6} \mathrm{O}_{20}\right)(\mathrm{OH}, \mathrm{F})_{4}$ & 1 & $\mathbf{3 0}$ \\
\hline Caulinita $-\mathrm{Al}_{2} \mathrm{O}_{3} \mathrm{SiO}_{2}$ & $5-7$ & $\mathbf{2 8 ; 3 0}$ \\
\hline Zircônio & 4 & $\mathbf{2 8}$ \\
\hline Cromita & $5,6-7,2$ & $\mathbf{2 8}$ \\
\hline Feldspato & $1,4-1,6$ & $\mathbf{3 0}$ \\
\hline
\end{tabular}

Segundo LEAL FILHO [28], além da atração eletrostática existirão também atrações de Van der Walls que seriam responsáveis pelas interações laterais entre as cadeias 
carbônicas. O nitrogênio protonizado ou quaternarizado seria atraído pelos sítios negativos da interface mineral/solução. Portanto, os íons positivamente carregados se adsorvem como contra-íons na dupla camada elétrica da superfície das partículas negativas, diminuindo a magnitude do potencial zeta das partículas (apenas zerando, sem reversão do seu sinal) e transformando o caráter hidrofílico da superfície em hidrofóbico. Além disso moléculas de derivados de aminas não ionizadas atuam como tensoativos não iônicos preenchendo o espaço deixado na superfície devido a repulsão lateral das cargas positivas, auxiliando na formação de um filme compacto e hidrofóbico.

Alguns fatores muito importantes estão associados ao tipo de adsorção que a amina realiza sobre os oximinerais e estão ilustrados na figura 24 , cujas explicações são apresentadas a seguir [29]:

a - A adsorção é do tipo eletrostática e ocorre individualmente através de íons amina $\left(\mathrm{R}-\mathrm{NH}_{3}{ }^{+}\right)$;

b - Com o aumento da concentração do coletor, inicia-se a formação de hemi-micelas ou íons associados na interface mineral/solução. Neste caso ocorrem interações entre as cadeias hidrocarbônicas dos coletores por forças laterais de Van der Walls. Tais hemimicelas podem ser entendidas como cátions polivalentes podendo estar combinados com moléculas de aminas livres, isto é, neutras $\left(\mathrm{R}-\mathrm{NH}_{2}\right)$. Estas associações moleculares na interface mineral/solução teriam sua parte polar voltada para o mineral e sua parte apolar direcionada para o interior da solução. O início da formação de hemi-micelas coincide com o aumento na flotabilidade dos oximinerais;

c - Com o aumento de concentração do coletor catiônico e das frações não iônicas, a camada de moléculas adsorvidas se torna cada vez maior e mais compacta até a formação de um filme verticalmente orientado e densamente empacotado.

d - Em concentrações ainda maiores ou iguais à CMC do coletor, ocorreria à adsorção de uma segunda camada, cujas moléculas apresentariam orientação reversa. Devido a esse fenômeno, ocorre a queda da flotabilidade do mineral.

Todos os efeitos descritos em a, b, c e d são ilustrados na figura 11.
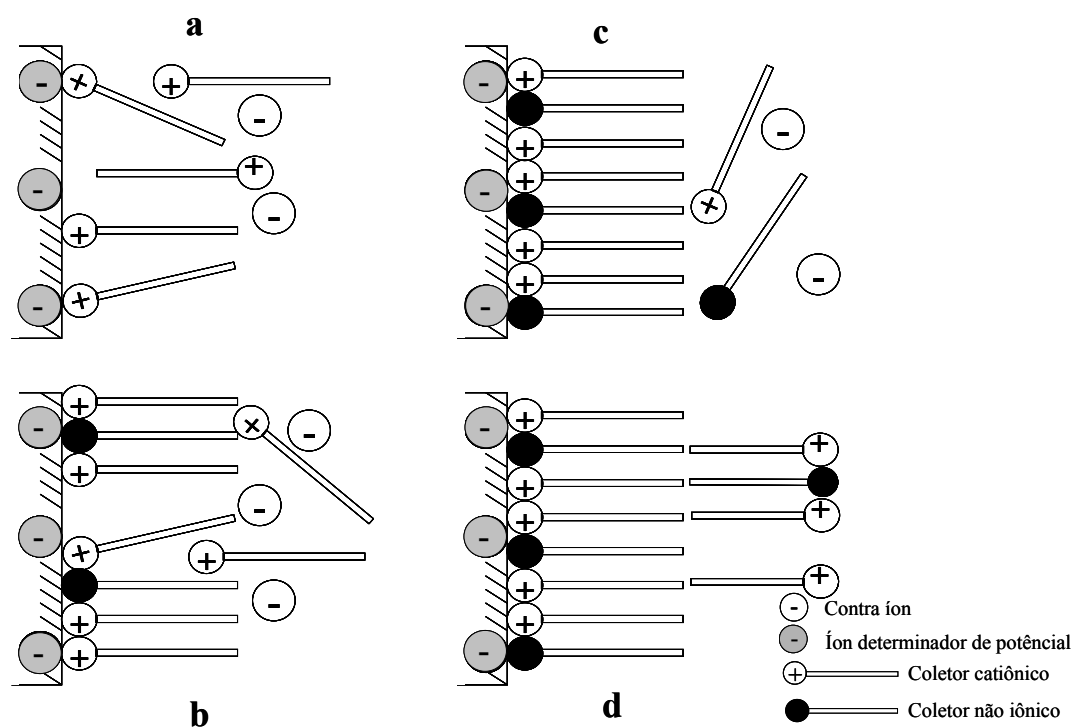

Figura 11: Representação esquemática da adsorção de coletores catiônicos (aminas) com a dupla camada elétrica até a formação de hemi-micelas [31]. 


\section{2 - Flotação de sais solúveis com aminas graxas}

Existem diversos autores que têm estudado o mecanismo de flotação de sais solúveis, [26;30 - 32] mas ainda existe um grande hiato na compreensão exata desse mecanismo. A teoria mais atual que busca explicar o mecanismo [26;34], sugere que a estrutura da água interfacial e os diferentes estados de hidratação dos sais solúveis seriam os parâmetros mais importantes a serem considerados e as propriedades eletrostáticas da superfície não estariam governando o mecanismo de adsorção.

Com o objetivo de determinar a força relativa da superfície de hidratação, HANCER ET AL [26], avaliaram o ângulo de contato $(\theta)$ de haletos de sódio e potássio em salmouras saturadas na ausência de coletores. O resultado de $\theta$ é apresentado juntamente com a figura 12. Segundo a literatura [26], os íons presentes nos sais, atuam de maneira distinta quanto à formação da estrutura da água interfacial. $\mathrm{Na}$ halita $(\mathrm{NaCl})$, os íons $\mathrm{Na}^{+}$seriam responsáveis pela formação de um leito de hidratação mais compacto e estruturado, que impediria a aproximação da amina na superfície. Por outro lado, existem sais cujos íons ( $\mathrm{K}^{+}$) são capazes de tornar essa barreira menos densa, facilitando a quebra da estrutura de hidratação e permitindo a formação de pontes de hidrogênio entre o coletor e o mineral e a conseqüente adsorção.

De acordo com os conceitos ilustrados na figura 12, as camadas de água na interface mineral/solução são menos ordenadas e compactas no $\mathrm{KCl}$ do que aquelas presentes no $\mathrm{NaCl}$. Devido a esse fator, a amina teria capacidade de romper esse leito de hidratação e adsorver na silvita preferencialmente à halita.

A importância da formação das pontes de hidrogênio entre coletor e mineral salino também seriam confirmadas quando se tenta flotar $\mathrm{KCl}$ com aminas secundárias ou terciárias. Esses compostos são menos capazes de formar ligações de hidrogênio, e, por isso, são péssimos agentes de flotação para a silvita.
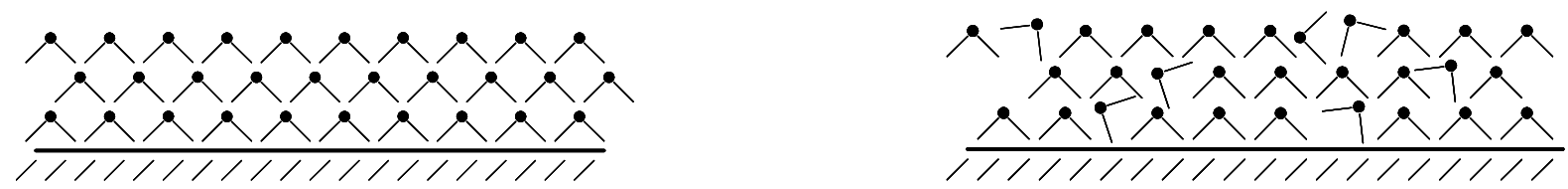

$\mathrm{NaCl}\left(\theta=0^{\circ}\right)$

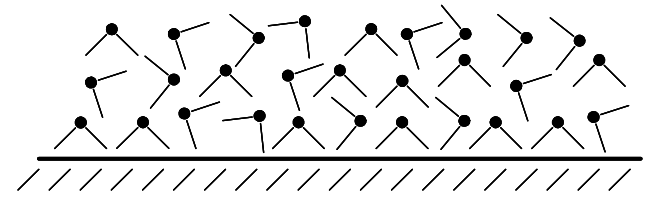

$\mathrm{KCl}\left(\theta=8^{\circ}\right)$

$\mathrm{KI}\left(\theta=25^{\circ}\right)$

Figura 12: Estrutura da água interfacial na superfície de $\mathrm{KI}, \mathrm{KCl}$ e $\mathrm{NaCl}$. Força relativa do íon $\mathrm{Na}^{+}$ em estruturar as moléculas de água $\mathrm{NaCl}$ comparativamente ao KCl e KI [26].

Essa teoria é complementada por TITKOV [34], que postula que os íons $\mathrm{Na}^{+}$reduzem a mobilidade da fase aquosa no leito de hidratação enquanto que os íons $\mathrm{K}^{+}$apresentam um efeito contrario. Também por isso, as aminas teriam facilidade de adsorver na superfície da silvita preferencialmente à halita. A principal causa desse efeito advém do sódio ter um tamanho iônico menor que do potássio e a energia de hidratação do primeiro ser também 
maior que do segundo. A tabela 7 mostra os raios iônicos e as energias de hidratação para vários íons.

Tabela 7: Características da hidratação de alguns íons em solução eletrolítica a 26 ${ }^{\circ} \mathrm{C}$ [34].

\begin{tabular}{|c|c|c|}
\hline Íon & Raio iônico $\left(10^{-3} \mu \mathrm{m}\right)$ & Energia de hidratação $(\mathrm{kJ} / \mathrm{g}$-íon $)$ \\
\hline $\mathrm{Na}^{+}$ & 0,95 & 422,9 \\
\hline $\mathrm{K}^{+}$ & 1,33 & 339,1 \\
\hline $\mathrm{Mg}^{2+}$ & 0,65 & 1943,9 \\
\hline $\mathrm{Cl}^{-}$ & 1,81 & 351,7 \\
\hline
\end{tabular}

É praticamente um consenso entre os usuários e pesquisadores, que as aminas primárias de cadeias longas ( $>16$ carbonos ) são os melhores produtos para flotar a silvita, entretanto podem existir muitas variações dentro dessa família de aminas.

O aumento da temperatura da salmoura sempre prejudica a flotação [33;34]. Duas explicação podem ser atribuídas a esse fenômeno:

i. As aminas têm sua solubilidade aumentada com o aumento da temperatura, e no processo de flotação da silvita, é necessário que existam aminas não solubilizadas para que os resultados sejam otimizados [33]. As aminas araquídicas (C20) e eurúcicas (C22) são as preferidas nessa situação.

i.i. Com o aumento da temperatura, haveria uma redução no ângulo de contato medido na superfície do $\mathrm{KCl}$ devido à extensão do leito de hidratação dos íons $\mathrm{Cl}^{-}$. $\mathrm{O}$ aumento da hidratação da silvita reduz a adsorção das aminas e recuperação como consequência. A figura 13 mostra a diminuição do ângulo de contato da silvita e da halita em função do aumento da temperatura, corroborando com essa teoria [34].

Outro fator importante que diz respeito às características da amina é o seu grau de saturação, ou índice de iodo (IV). Como já discutido em 2.4, quanto menor o IV menor será o grau de saturação do derivado nitrogenado e quanto maior o IV pior será o resultado da flotação para esses sais solúveis. Aminas insaturadas são mais facilmente solubilizadas que suas congêneres saturadas o que dificulta a flotação [32].

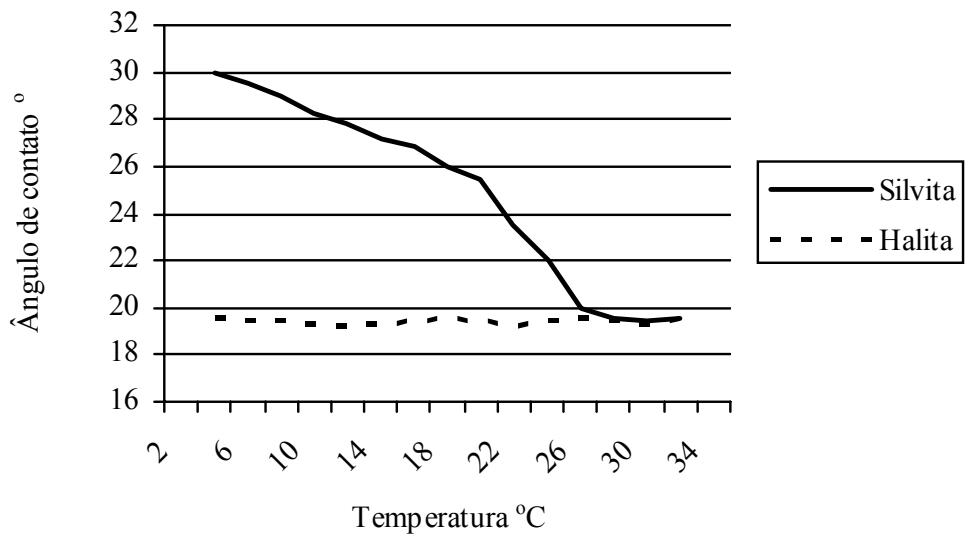

Figura 13: Efeito do aumento da temperatura na hidrofilicidade da halita e da silvita [34]. 


\section{CONSIDERAÇÕES FINAIS}

A literatura [33], aliada às informações obtidas juntamente às empresas de mineração, permite o detalhamento dos produtos utilizados em cada uma das usinas de concentração (tabela 8) e que utilizam coletores derivados de aminas.

Raramente, podem ser observados problemas operacionais advindos da variação da qualidade do coletor utilizado, cujo diagnóstico é difícil e requer uma grande dose de experiência do usuário. Na tabela 9, apresentam-se informações sobre as variações de qualidade mais comuns de serem observadas nos derivados de aminas e seu possível impacto no processo de flotação.

Uma sugestão para outros pesquisadores, é que seja investigado o desempenho de outros tipos de aminas que não os quaternários de amônio ( tipo brometo de cetil trimetil amônio ou brometo de dodecil dimetil amônio ) e as aminas primárias tipo dodecilamina. Com poucas exceções, quase toda literatura disponível baseou seus estudos e conclusões na avaliação desses produtos. Atualmente existem ácidos graxos ramificados, que podem ser usados na síntese de derivados de aminas também ramificados e cujo desempenho na flotação é imprevisível e uma incógnita. Além do mais, o tema de saturação das cadeias é praticamente inexplorado pela literatura.

Tabela 8: Minas e minérios que utilizam coletores amínicos e sua respectiva dosagem.

\begin{tabular}{|c|c|c|c|c|}
\hline Minério & Mina & Usina & Tipo de Coletor & Dosagem $\mathrm{g} / \mathrm{t}$ \\
\hline \multirow[t]{7}{*}{ Hematita } & Alegria & CVRD & Eteramina & 100 \\
\hline & Conceição & CVRD & Eteramina & 44 \\
\hline & Timbopeba & CVRD & Eteramina & 40 \\
\hline & Capitão do Mato & MBR & Eteramina & 44 \\
\hline & Casa da Pedra & $\mathrm{CSN}$ & Eteramina & 55 \\
\hline & Cauê & CVRD & Eteramina & 44 \\
\hline & Germano & Samarco & $\begin{array}{l}\text { Eteramina e } \\
\text { eterdiamina }\end{array}$ & $100^{16}$ \\
\hline Willemita & Vazante & CMM & Aminas primárias & 130 \\
\hline Calamina & Vazante & CMM & Aminas primárias & 350 \\
\hline \multirow[t]{2}{*}{ Pirocloro } & Araxá & CBMM & Diamina & 140 \\
\hline & Catalão & Anglo American & $\begin{array}{l}\text { Eteramina e } \\
\text { diamina }\end{array}$ & $\begin{array}{c}150 \text { (finos) e } \\
300 \text { (grossos) }\end{array}$ \\
\hline Calcita & Mogi da Cruzes & Imerys & $\begin{array}{l}\text { Mistura de } \\
\text { polietileno aminas } \\
\text { com sais de amônio } \\
\text { quaternário }\end{array}$ & 180 \\
\hline Magnesita & Brumado & Magnesita & $\begin{array}{l}\text { Mistura } r \text { de } \\
\text { polietileno aminas } \\
\text { com sais de amônio } \\
\text { quaternário }\end{array}$ & 80 \\
\hline Apatita & Cajati & Bunge & Alquil Sarcosinato & $\begin{array}{l}200 \text { (finos) e } \\
50 \text { (grossos) }\end{array}$ \\
\hline Silvita & taquari-vassouras & CVRD & Amina primária & $200-220$ \\
\hline
\end{tabular}


Tabela 9: Possíveis problemas de qualidade que podem ocorrer com os derivados de aminas e sua esperada interferência na flotação.

\begin{tabular}{|c|c|c|c|}
\hline Compostos & $\begin{array}{l}\text { Possíveis problemas } \\
\text { de fabricação }\end{array}$ & $\begin{array}{l}\text { Como controlar a } \\
\text { ocorrência dos } \\
\text { problemas }\end{array}$ & $\begin{array}{l}\text { Possíveis problemas no } \\
\text { desempenho } \\
\text { flotação }\end{array}$ \\
\hline $\begin{array}{l}\text { Aminas } \\
\text { primárias }\end{array}$ & $\begin{array}{l}\text { Alto teor de aminas } \\
\text { secundárias e alto } \\
\text { índice de iodo }\end{array}$ & $\begin{array}{l}\text { IA total e IA aminas } \\
\text { secundárias } \\
\text { IV }\end{array}$ & $\begin{array}{ll}\text { Alteração } & \text { na } \\
\text { solubilidade e queda na } \\
\text { recuperação }\end{array}$ \\
\hline Diaminas & Índice de iodo baixo & IV, IA & $\begin{array}{l}\text { Alteração na } \\
\text { solubilidade e queda na } \\
\text { recuperação }\end{array}$ \\
\hline $\begin{array}{l}\text { Eteraminas e } \\
\text { eterdiaminas }\end{array}$ & $\begin{array}{l}\text { Alto teor de amina } \\
\text { secundária, presença } \\
\text { de álcool livre e } \\
\text { presença de ACN }\end{array}$ & $\begin{array}{l}\text { IA total e IA aminas } \\
\text { secundárias }\end{array}$ & $\begin{array}{l}\text { Maior estabilidade da } \\
\text { espuma (ACN), queda } \\
\text { na recuperação }\end{array}$ \\
\hline $\begin{array}{l}\text { Sais } \\
\text { quaternários } \\
\text { de amônio }\end{array}$ & $\begin{array}{l}\text { Alto teor de sais de } \\
\text { sódio, aumento do } \mathrm{pH} \\
\text { e amina livre alta }\end{array}$ & IA & $\begin{array}{l}\text { Possível variação de } \mathrm{pH} \\
\text { no condicionador }\end{array}$ \\
\hline $\begin{array}{l}\text { Alquil } \\
\text { sarcosinato }\end{array}$ & $\begin{array}{l}\text { Presença indesejada de } \\
\text { aminas primárias e } \\
\text { secundárias } \\
\text { dialquilicas }\end{array}$ & $\mathrm{IA}, \mathrm{IN}$ & Perda de seletividade \\
\hline
\end{tabular}

Recentemente, HERRERA-URBINA [34], faz uma análise das tendências de desenvolvimentos de coletores utilizados em flotação. No que tange as aminas, ele identifica a tendência dos fabricantes de coletores que buscam desenvolver produtos específicos para cada mina e minério segundo dois critérios:

i. Seleção de um grupo polar especifico capaz de adsorver em um sítio particular.

i.i. A utilização de um grupo não polar suficientemente hidrofóbico que permita que a partícula se junte com a bolha fortemente superando as forças hidrodinâmicas que podem desestabilizar esse sistema.

Portanto, o trabalho de desenvolvimento de novas moléculas deve estar "amarrado" ao conhecimento das propriedades hidrodinâmicas do processo de flotação.

O tema das aminas utilizadas em flotação, apesar de ter mais de 60 anos, ainda pode ser considerado bastante vasto e longe de estar esgotado. Espera-se que esse texto auxilie para melhor compreender esses compostos químicos e ajude a aproximar ainda mais os usuários e produtores para o constante desenvolvimento de novos produtos.

\section{REFERÊNCIAS}

1 - BATHINA, H.B.; RECK, R.A. Fatty Amines. In: Kirk Othmer: Encyclopedia of chemical technology, 3.ed. New York: John Wiley\& Sons, 1978 v.2, p.283 - 293.

2 - ROSE, A.; ROSE, E. The condensed chemical dictionary. 5.ed. New York: Reinhold Publishing Company, 1957. 
3 - SOLOMONS, G.T.W. Organic chemistry. 6.ed. New York: John Wiley \& Sons 1996, p.899- 962 .

4 - BATHINA, H.B.; RECK, R.A. Fatty Amines. In: Kirk Othmer: Encyclopedia of chemical technology, 3.ed. New York: John Wiley\& Sons, 1978 v.2, p.283 - 293.

5 - PEL, A. Versatile and sustainable source of raw materials for the surfactants industry. Gouda: Uniquema, 1999.

6 - WITTCOFF, H.A.; REUBEN, B.G. Industrial organic chemicals. New York: John Wiley \& Sons, cap.13, p.359-379.

7 - POTTS, R.H.; MUCKRHEIDE, V.J. Fatty acids production. In: PATTISSON E.S. (Ed) Fatty acids and their industrial applications. New York: Marcel Dekker, 1968, p.21-44.

8 - METCALF, L.D. Traditional analytical chemistry of fatty acids and their derivatives. Journal of American Oil Chemists Society, 1979. vol. 56, p.786-789.

9 - METCALF, L.D. Recent advances in the analytical chemistry of fatty acids and derivatives. Journal of American Oil Chemists Society, 1979, vol. 56, p. 819-822.

10 - AKZO NOBEL LTDA. Surface chemistry - general catalog of nitrogen derivatives. Dobbs Ferry: Akzo Nobel LLC, 2002, Publication SC02-11. Disponível em www.surface.akzonobe.usa.com. Acesso em 10 de Janeiro de $2005 .{ }^{*}$

11 - NOSTRAND, V.; The condensed chemical dictionary. 9ed, New York: McGraw Hill, 1977.

12 - PIORR, R., Structure and application of surfactants. In: FALBE, J. Surfactants in consumer products. Berlin: Spring-Verlag, 1987, p.19-21

13 - VERBEEK, H., Historical Review, In: FALBE, J. Surfactants in consumer products, Berlin: Spring-Verlag, 1987, p.1-4.

14 - OSIPOW, L.I. Surface chemistry - theory and industrial applications. New York: American Chemical Society / Reinhold Publishing, 1963.

15 - GOULD, R.F. Advances in chemistry series. [s.1.]: American Chemical Society Applied publications, 1961.p. 296-311.

16 - ATTWOOD, D.; FLORENCE A.T. Surfactants systems, their chemistry, pharmacy and biology. London: Chapman \& Hall, 1983, cap.3.7.

17 - SCHWARTZ, A.M.; PERRY, J.W.; BERCH, J. Surface active agents and detergents. New York: Interscience Publishers, 1958. v.II, p.255-269.

18 - MOILLIET, J.L.; COLLIE, B.; BLACK, W. Surface activity - the physical chemistry, technical applications and chemical constitution of synthetic surface active agents. 2ed. London: E.\&F.N.Spon , 1961. p. 56-61. 
19 - ROBBINS, M.L. Micellization, solubilization and microemulsions. ed. MITTAL, K.L. New York: Plenum press, 1977.

20 - WALSTON, D.; MANSER, R.M. Some factors affecting the limitations conditions in cationic flotation of silicates. Transactions AIME, 1968, 77: C57.

21 - SHINODA, K.; FRIBERG, S. Emulsions and solubilization. New York: John Wiley \& Sons, 1986, p. 55-71.

22 - VAN GINKEL, C.G. Biodegradation of cationic surfactants - an environmental perspective. In: Handbook of detergents, New York: Marcel Dekker, 2004, part B, cap. 25, p. $523-549$.

23 - FUERSTENAU, D.W.; HERRERA-URBINA, R. Adsorption of cationic surfactants and the flotation of minerals. In: RUBINGH, D. N. Cationic surfactants: physical chemistry-surfactants series, New York: Marcel Dekker, 1991, v.37 p.407-447.

24 - HANCER, M.; CELIK, M.S.; MILLER J.D. The significance of interfacial water structure in soluble salt formation systems. Journal of Colloid and Interface Science, v.235, p. 150-161, 2001.

25 - SOMASUNDARAN, P; RAMACHANDRAN, R. Surfactants in flotation. In: Surfactants in chemicals, New York: Marcel Dekker, 1988. v.28 p.195-235.

26 - LEAL FILHO, L.S. A seletividade na separação apatite/silicates por flotação: Subsídios para a solução de problemas tipicamente brasileiros. 1999, 180p. Tese (Livre Docência) - Escola Politécnica da Universidade de São Paulo, São Paulo, 1999.

27 - MANSER, R.M. Handbook of silicate flotation. Stevenage: Warren Spring, 1973. p.37-179.

28 - LEAL FILHO, L.S. Flotação de oximinerais: teoria e prática voltada à solução de problemas brasileiros. São Paulo: Escola Politécnica da Universidade de São Paulo, 2000. p. 152-154. Fundamentação teórica utilizada para a prova pública oral de erudição, nos termos do edital 310/99. Concurso para Prof. Titular da Área de Tratamento de Minérios.

29 - FUESTENAU, M.C. Oxide and silicate flotation, In: MATIS, K.A. Flotation science and engineering. New York: Marcel Dekker, 1995. p.89-126.

30 - LEJA, J. Action of long chain amines in potash flotation. In: McKERCHER, R.M. (Ed.) Potash technology, Toronto: Pergamon Press, 1983, p. 623-629.

31 - LASKOWSKI, J.S. The colloid chemistry and flotation properties of primary aliphatic amines. In: SASTRY, K.S.V. / FUERSTENAU, M.C. (Ed.) Challenges in mineral processing. Littleton: SME, 1989. p.15-34. 
32 - TITKOV, S. Flotation of water-soluble mineral resources. International Journal of Mineral Processing, v. 74, p.107-113, 2004.

33 - SAMPAIO, J.A.; DA LUZ, A.B.; LINS, F.F., Usinas de beneficiamento de minérios do Brasil, Rio de Janeiro: CETEM/MCT, 2001.

34 - HERRERA URBINA, R. Recent developmens and advances in formulations and applications of chemical reagents used in froth flotation. Mineral processing \& extractive metallurgical review, v. 24, p. 139-182, 2003. 